\title{
CARACTERIZACIÓN SOCIOECONÓMICA Y TECNOLÓGICA DE LA PRODUCCIÓN DEL PLÁTANO EN EL BAJO OCCIDENTE DEL DEPARTAMENTO DE CALDAS
}

\author{
Libardo León-Agatón ${ }^{1}$ \\ Luis Fernando Mejía-Gutiérrez ${ }^{1}$ \\ Luz Mary Montes-Ramírez ${ }^{1}$
}

Recibido el 6 de mayo de 2014, aprobado el 23 de febrero de 2015 y actualizado el 30 de abril de 2015

DOI: 10.17151/luaz.2015.41.11

\section{RESUMEN}

El plátano es un cultivo estratégico para la seguridad alimentaria nacional constituyéndose en uno de los alimentos básicos más importantes a nivel socioeconómico por la oportunidad para la generación de empleos directos e indirectos, además de los ingresos que le puede aportar a la población rural. El objetivo fue realizar un diagnóstico para evaluar el grado de focalización del productor y el impacto de la intervención de las entidades encargadas en la transferencia de tecnología a través de programas de apoyo técnico y aspectos sociales, para contribuir con otras alternativas que ayuden a mejorar los ingresos del sector.

La caracterización se plantea también como instrumento y fuente de información pública al alcance de instituciones que deseen implementar nuevos programas de mejoramiento que sirvan para el desarrollo socioeconómico y tecnológico del sector. Mediante encuesta a productores se evalúan aspectos relacionados con el perfil de los productores, establecimiento de cultivos, actividad social, labores culturales, cosecha, poscosecha y comercialización. Los hallazgos mostraron que la mayoría de los productores son de avanzada edad y bajo nivel de escolaridad, poca capacidad de asociatividad y utilización de mano de obra contratada tradicionalista. Los cultivos son pequeños, sin tecnificar, de manejo deficiente por aplicación inadecuada de las Buenas Prácticas Agrícolas (BPA) como el uso de agroquímicos prohibidos, deficiencias en procesos de desinfección, productivo, cosecha y poscosecha. Esta problemática influye de forma negativa en la calidad del producto y en la adecuada comercialización y rentabilidad.

\section{PALABRAS CLAVE}

Caracterización, productores, prácticas, plátano. 


\title{
SOCIO-ECONOMIC AND TECHNOLOGICAL CHARACTERIZATION OF BANANA PRODUCTION IN THE LOWER WEST REGION OF THE DEPARTMENT OF CALDAS
}

\begin{abstract}
Plantain is a strategic crop for national food security becoming one of the most important staple foods at the socioeconomical level because of the opportunity to generate direct and indirect employment in addition to the income generated for the rural population. The objective was to make a diagnosis to assess the degree of targeting of the producer and the impact of the intervention of the entities in charge of transfering technology through programs of technical and social support to help with other alternatives that allow improvement of the sector revenues.
\end{abstract}

The characterization is also raised as a tool and source of public information available to institutions wishing to implement new programs that serve to improve the socioeconomic and technological development of the sector. By means of a survey to producers, aspects related to the producers' profile, crop establishment, social activity, cultural practices, harvesting, postharvest and marketing were evaluated. The findings showed that most producers are elderly and low educational level, low capacity of association and use of traditional hired labor. The crops are small, without technification, of poor management because of inadequate implementation of Good Agricultural Practices (GAP) and the use of prohibited chemicals, deficiencies in disinfection, production, harvest and postharvest processes. This problem influences in a negative way the quality of the product and proper commercialization and profitability.

\section{KEY WORDS}

Characterization, producers, practices, banana.

\section{INTRODUCCIÓN}

El plátano del género Musa, pertenece a un sistema de cultivo permanente y se produce en diferentes agroecosistemas (CORPOICA, 2002; INFOAGRO, 2005) por lo que es uno de los productos agrícolas con mayor área sembrada en Colombia. Su consumo es predominantemente en fresco y de comercialización inmediata, presentando características especiales de mercadeo comunes a otros productos perecederos que conforman un sistema complejo de producción y distribución, por cuanto en su proceso intervienen muchos productores, intermediarios y pocos mayoristas, quienes son los encargados de distribuir el producto hacia el consumidor final (CCl, 2000). En el año 2010 Colombia participó con el $7,9 \%$ de la producción mundial de plátano y ocupó el tercer lugar entre los países con mayor producción, después de Uganda y de Ghana. El país presenta una ventaja 
comparativa en el rendimiento del cultivo, en el ámbito mundial, con 8,5 t ha-1

El área total de los cultivos permanentes reportados por la Encuesta Nacional Agropecuaria-2012 correspondió a 1'281.965 ha, donde el cultivo de café participó con el $56,3 \%$ equivalentes a 122.110 ha, seguido por el plátano con una participación del $12,5 \%$ equivalentes 209.931 ha del área establecida. A escala nacional, el plátano sigue siendo uno de los productos alimenticios más importantes ya que participa con el 38,5\% de la producción total agrícola, ocupando el primer lugar después de la caña panelera con el 26,9\% y el café $12,5 \%$ (DANE, 2013). Los departamentos de Antioquia, Quindío, Arauca, Caldas, Meta, Valle, Risaralda, Tolima, Nariño y Cauca, en su orden, son los mayores productores y representan el $72 \%$ de la producción y el $65 \%$ del área sembrada, que para el 2010 fue de 368.392 ha (AGRONET, 2012).

El cultivo del plátano se ha constituido en un renglón de gran importancia socioeconómica, desde el punto de vista de seguridad alimentaria y generación de empleo; también ha pertenecido a la economía campesina donde ha sido utilizado, fundamentalmente en la dieta alimenticia y como un cultivo capitalizador de dicha economía. En el país más de la mitad del área cultivada pertenece a pequeños productores. Infortunadamente en los últimos años, por problemas fitosanitarios graves como la Sigatoka negra, Sigatoka amarilla y el Moko (Ramírez et al., 2013) se ha reducido la rentabilidad del cultivo al aumentarse los costos de producción en más del 300\% y han hecho que los pequeños productores descuiden sus cultivos lo que no ha permitido mayores rendimientos por hectárea (Moreno, Blanco y Mendoza, 2009).

La tendencia de la demanda actual y futura de plátano es por calidad viéndose actualmente afectada por factores como el desconocimiento de muchos productores para la adecuada producción, comercialización y en aspectos técnicos relacionados con apariencia, tamaño, peso y presentación de los frutos por lo que las cadenas especializadas, las centrales mayoristas y la agroindustria han establecido sus propios criterios que vienen afectando los ingresos (menor rentabilidad en los procesos productivos), menor participación comunitaria e inestabilidad del campesino en sus parcelas (Espinal, 2005; Mejía, 2013).

De acuerdo a lo anterior, esta investigación planteó mediante esta caracterización socioeconómica y tecnológica de la producción del plátano en el bajo Occidente del departamento de Caldas conocer sobre el grado de focalización de los productores y el impacto de la intervención de las entidades encargadas en la transferencia de tecnología a través de programas de apoyo técnico y aspectos sociales y organizativos de alcance departamental, para la mejora de los ingresos del sector. 


\section{MATERIALES Y MÉTODOS}

Este trabajo se realizó en el bajo Occidente del departamento de Caldas (San José, Viterbo, Anserma y Belalcázar) por ser una de las zonas de mayor producción de plátano.

\section{Métodos}

\section{Recolección de la información y variables}

La información se recolectó mediante encuesta a los productores y comercializadores de plátano para conocer el estado social, económico y tecnológico del sector.

En lo social se indagaron aspectos como: edad, nivel de escolaridad, actividad principal, tipo de núcleo familiar.

En lo económico: nivel de asociatividad, mano de obra, financiación y comercialización (forma y lugar de venta, precio racimo, peso racimo vs. productores, forma de pago, fijación del precio).

En lo tecnológico: asistencia técnica, establecimiento del cultivo (tamaño de la finca, permanencia y uso de la tierra, edad de la plantación, sistema de producción, variedad cultivada, criterio para escoger el lote, orientación del cultivo), siembra (época de siembra, elección distancia de siembra, y sistema de trazo), selección de semillas (criterio de selección y obtención de semillas, forma de siembra), manejo del cultivo (criterio de fertilización, control de malezas, control químico), manejo de enfermedades (desinfección de herramientas, plagas), labores culturales (deshoje, descalcete, descoline y destronque), cosecha y poscosecha (forma de cosechar, forma de empaque, destino de residuos).

\section{Fuentes de información}

Las fuentes de información fueron de tipo primario como productores seleccionados aleatoriamente, técnicos de la cadena de plátano de la Secretaría de Agricultura del departamento de Caldas, Alfonso Martínez, Julio J. Becerra y Javier Villamil. Las fuentes de información secundaria las Unidades Municipales de Asistencia Técnica Agropecuaria (UMATAS) de los municipios del bajo Occidente de Caldas y los Centros Provinciales de Gestión Agroempresarial (CPGA).

\section{Tamaño muestra}

El cálculo del tamaño de muestra se determinó de acuerdo a los datos suministrados por la Gobernación del departamento de Caldas en el RUAT (Registro de Usuarios de Asistencia Técnica del 2008) (Ec.1). La encuesta se realizó a 96 productores de los 1514 que corresponden a los municipios del bajo Occidente del departamento de Caldas. 


$$
n=\frac{\sum_{L=1}^{L=3}\left(N_{i}^{2} P_{i} q_{i}\right) / w_{i}}{(n-1)^{2} e^{2} / 4+\sum N_{i} P_{i} q_{i}}\left(E_{c} .1\right)
$$

Donde:

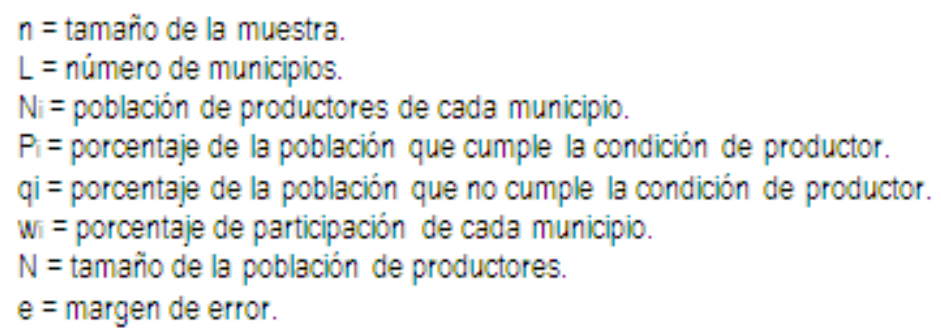

\section{Análisis estadístico}

Se utilizó estadística descriptiva agrupando los datos en tablas de frecuencias expresadas en unidades porcentuales con relación al total de la población encuestada por cada criterio, con margen de error de $1,5 \%$.

\section{RESULTADOS Y DISCUSIÓN}

\section{Caracterización socioeconómica}

En la administración del cultivo del plátano Dominico-Hartón en los municipios del bajo Occidente del departamento de Caldas, ya sea monocultivo o asociado, el hombre es quien toma todas las decisiones sobre el manejo de los sistemas de producción y la mujer desempeña un papel secundario en la toma de decisiones, a pesar de que actualmente ha habido un cambio respecto al papel protagónico de este tipo de actividades en el sector rural particularmente en el sistema de producción del plátano.

Con respecto a la edad se encontró que el 33\% de la población se encuentra entre los 41 y 50 años (Tabla 1).

Tabla 1. Edad promedio de los productores de plátano

\begin{tabular}{llllll}
\hline \multicolumn{7}{l}{ Edad de la población } \\
\hline Rangos de edad [años] & $20-30$ & $31-40$ & $41-50$ & $51-60$ & $>$ a 61 \\
\hline Porcentaje [\%] & 6,79 & 20,21 & 33,00 & 23,4 & 16,6 \\
\hline
\end{tabular}

Fuente: los autores.

El nivel de escolaridad de los cultivadores de plátano en general es bajo, aunque entre la población se encuentren personas con formación de postgrado, profesional y técnico, pero en su mayoría se encuentra con formación básica o primaria (39,36\%). 
Esto explica la falta de eficiencia de los medios y las metodologías hasta ahora empleados para la transferencia de tecnología, como manuales, cartillas divulgativas y boletines técnicos. La Ley 607 de 2000 reglamenta la asistencia técnica directa rural a través de las UMATAS y en consonancia con el Sistema Nacional de Ciencia y Tecnología, reactivando así el sector agropecuario y cuya función es la transferencia de nuevas tecnologías a los pequeños productores de manera directa y gratuita, pero en este caso ha sido difícil la adopción porque aunque se encuentre en la mayoría un nivel de escolaridad básico hay muchas deficiencias y diferencias en aspectos como las tendencias culturales, otros niveles educativos y medios de comunicación para la formación que las instituciones en algunos casos no pueden controlar.

La actividad principal del productor de plátano es prácticamente agrícola representada en un $83 \%$ de los cultivadores encuestados, derivan su sustento exclusivamente del cultivo del plátano y café; siendo el cultivo del plátano en un porcentaje mayor $(95,74 \%)$ y el café (83\%). Sin embargo, un pequeño porcentaje de ellos (21\%) utilizan como medio de capitalización el cultivo de otros productos como frutas y verduras tales como cítricos, cacao, yuca, aguacate, entre otros, pero en conjunto también trabajan con la explotación ganadera y porcícola para aumentar su rentabilidad. Su decisión para cultivar en orden de prioridad se basa en la rentabilidad (67\%), tradición (13\%), fertilidad (12\%), fácil manejo (7\%) y conocimientos (1\%). La rentabilidad es su principal atractivo, además por tener un mercado asegurado durante casi todo el año, presentando un mayor precio en época de cosecha de café.

En los últimos años, en lo que respecta a su economía, los productores de plátano han tenido que competir contratando mano de obra representada en trabajadores más jóvenes y eficientes que prefieran estas actividades (52\%), familiar (41\%) y contratada familiar (6\%). El $67 \%$ reciben asistencia técnica mediante asesorías especializadas de organismos como las UMATAS, las alcaldías, el Sena o el Comité de Cafeteros. Para el manejo de los cultivos el $73,4 \%$ de los productores utilizan recursos propios, el 15\% recurren a la financiación y ambas alternativas el 12\%. Realmente se limitan por la gran cantidad de requisitos exigidos por los bancos, el factor riesgo y los altos intereses. Estos resultados ponen en evidencia la ineficiencia e insuficiencia de los recursos que debe inyectar el Fondo Municipal de Asistencia Técnica Directa Rural, la cual financia la asistencia técnica, servicios conexos y de soporte para el desarrollo rural (Ley 6007 de 2000). Otro factor es la poca capacidad de gestión y destinación de recursos nacionales e internacionales para el beneficio de los pequeños productores.

En cuanto a la comercialización, el $83 \%$ se vende tal como sale de la producción y el $14 \%$ se clasifica en canastillas según peso y tamaño. El $43 \%$ se vende a través de intermediarios debido a las facilidades de transporte, reduciéndose sensiblemente las ganancias del productor, el 34\% en plazas de mercado, el 13\% a cadenas de supermercados y el $10 \%$ se exporta. El precio de venta/racimo es variable: el $50 \%$ se vende a $\$ 4000$, el $23 \%$ a 
$\$ 5000$, el $17 \%$ a $\$ 3000$ y solo el $10 \%$ a más de $\$ 6000$. Estos precios se correlacionan con el peso promedio/racimo, el cual es de $19 \pm 3 \mathrm{~kg}$. El peso del racimo depende de: tipo de suelo, altitud, clima, manejo del cultivo y de producción.

\section{Caracterización tecnológica}

Los productores encuestados en el bajo Occidente de Caldas manejan un sistema asociado para dar inicio al establecimiento del cultivo, en la mayoría de los casos el tamaño de las fincas son pequeñas, el 69,0\% tiene un área entre 1 y 10 ha, por lo cual se considera que el productor de plátano de Caldas es minifundista como se muestra en la Figura 1.

En lo referente al uso de la tierra, los productores con menos de 5 ha diversifican el plátano con otros cultivos como café y cítricos para satisfacer sus necesidades de consumo y el productor que cuenta con más de 10 ha no lo diversifica, ya que tiene contrataciones con cadenas de supermercados y para exportación. Sobre la permanencia, el 65\% de los productores se mantienen en su propio predio debido a las labores cotidianas que demanda este tipo de cultivos y el 35\% permanecen en otras áreas.

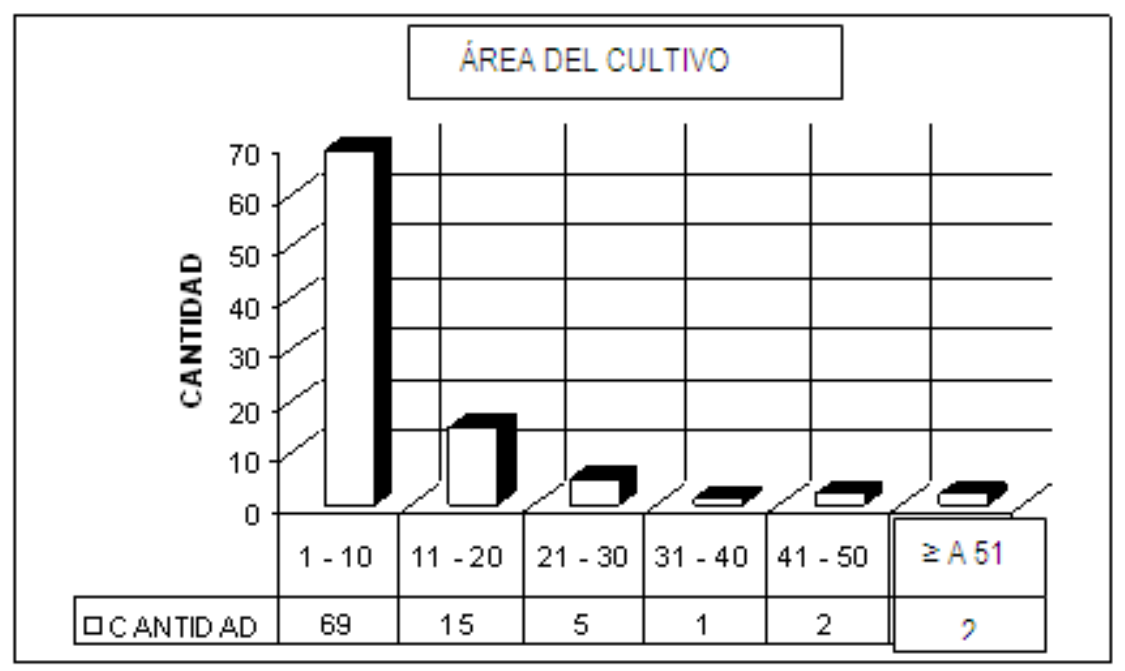

Figura 1. Tamaño de la finca por hectáreas.

La edad de las plantaciones no es homogénea (Figura 2), por prácticas de resiembra, por lo que se ven obligados a cosechar hasta tres veces por semana. Además, son pocas las plantaciones que tienen un trazo definido, lo cual repercute en los rendimientos de producción al no tener un mejor aprovechamiento de los suelos, el sistema recomendado es el triángulo o tres bolillos. 


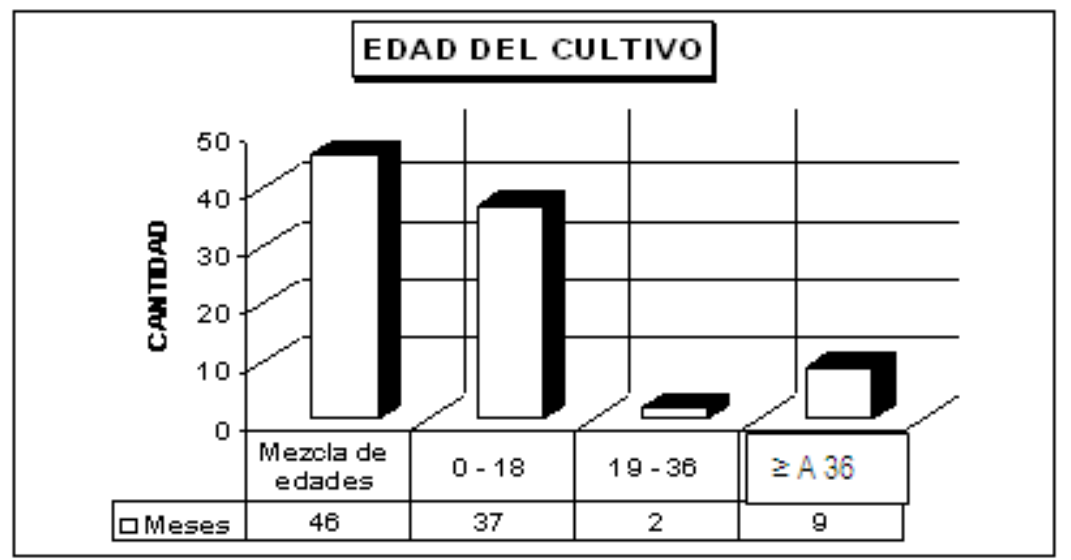

Figura 2. Edad de las plantaciones de plátano.

El sistema de producción predominante en el bajo Occidente del departamento de Caldas es el asociado con el 68\% de las explotaciones, incluyendo cultivos como café, yuca, maíz, frutas y cacao. La variedad de plátano más cultivada es DominicoHartón (90\%) (Figura 3).

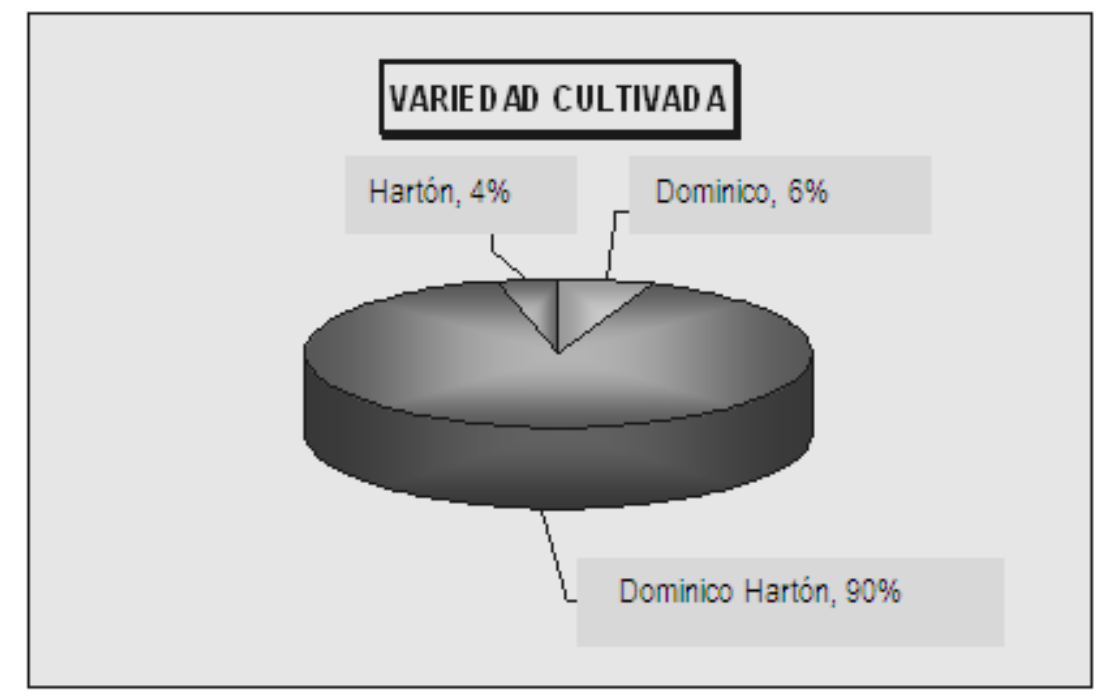

Figura 3. Variedades cultivadas.

Para escoger el lote se orientan hacia la siembra en lotes cercanos a su vivienda, con el fin de poder vigilar la plantación. En la Figura 4 se muestran los criterios de selección. En orden de importancia son: fertilidad, suelos, acceso a las vías, protección a barreras, disponibilidad de agua, etc. El 40,4\% de los productores realizan acondicionamiento apropiado del suelo, en ello encuentran beneficios referentes al aumento en el tamaño del racimo, reducción del ciclo vegetativo y persistencia de la plantación (Figura 4).

El 5\% de los productores orienta el cultivo de norte a sur para generar sombreado, evitando así la agresividad de las malezas. El $11 \%$ aplica este criterio según la zona montañosa de la cordillera, el $15 \%$ por la ubicación del cultivo de café, un $6 \%$ a 
través de la pendiente, el $2 \%$ en surcos, el $5 \%$ de oriente a occidente, el $2 \%$ al oriente y el $2 \%$ al norte. El $54 \%$ de los encuestados no realiza orientación del cultivo como se evidencia en la Figura 5.

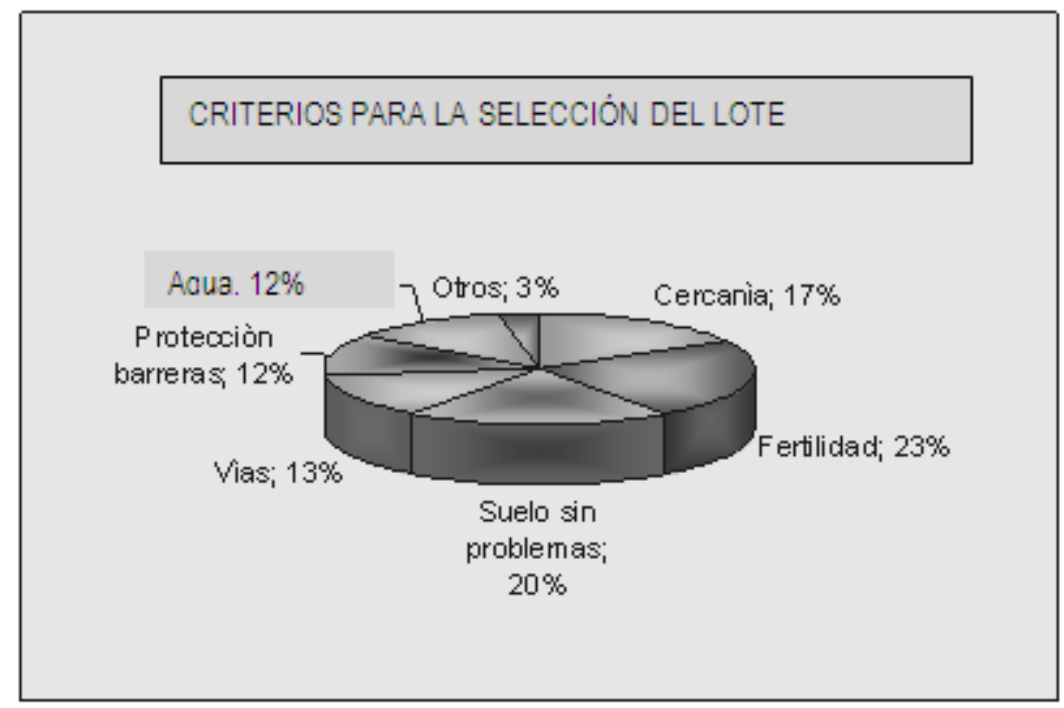

Figura 4. Criterios de selección del lote.

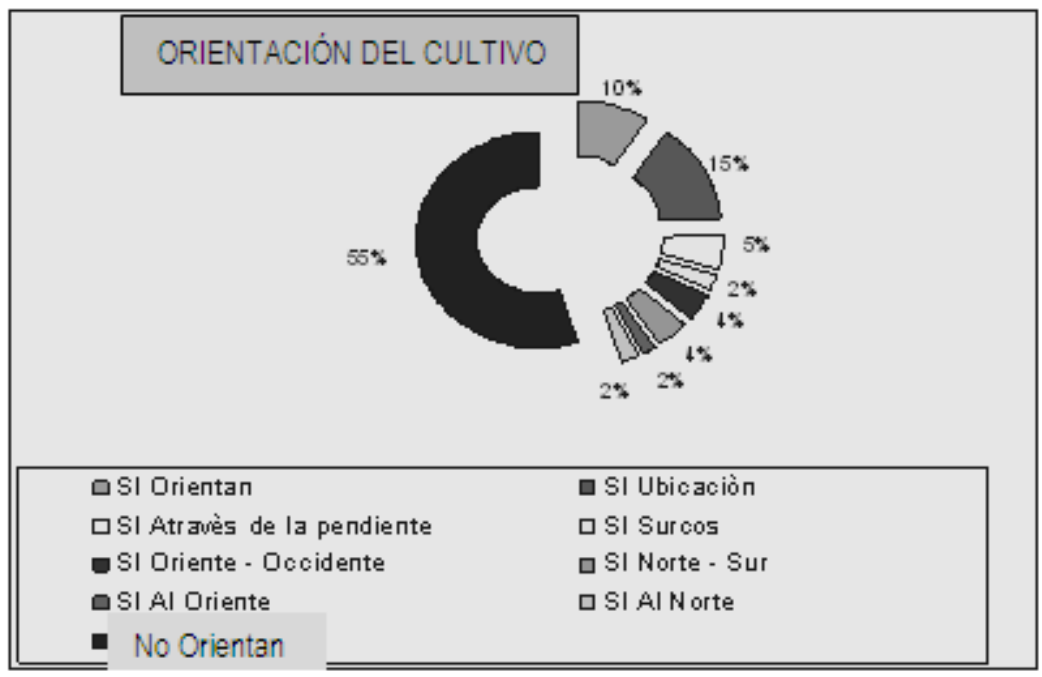

Figura 5. Orientación del cultivo.

El 50\% de los productores siembra en menguante (Figura 6). En los meses de septiembre, octubre y noviembre hay menos oferta, lo cual genera un aumento en los precios de comercialización, mientras que en el primer y segundo trimestre del año hay exceso de oferta y menos demanda, por lo tanto buenos precios al consumidor.

El productor tradicional aplica un sistema de trazo empleando distancias amplias entre 1100 a 1500 plantas por hectárea, y en la medida en que se va tecnificando el cultivo, se acortan las distancias. Sin embargo, el sistema de trazo aplicado es variado 
(trazo por barreras, trazos en cuadrado, trazos en triángulo y trazos en rectángulo). Las plantaciones tienen más de un corte y cuando no se resiembra se van perdiendo sitios disminuyendo la cantidad de plantas por área, según los encuestados (Figura 8).

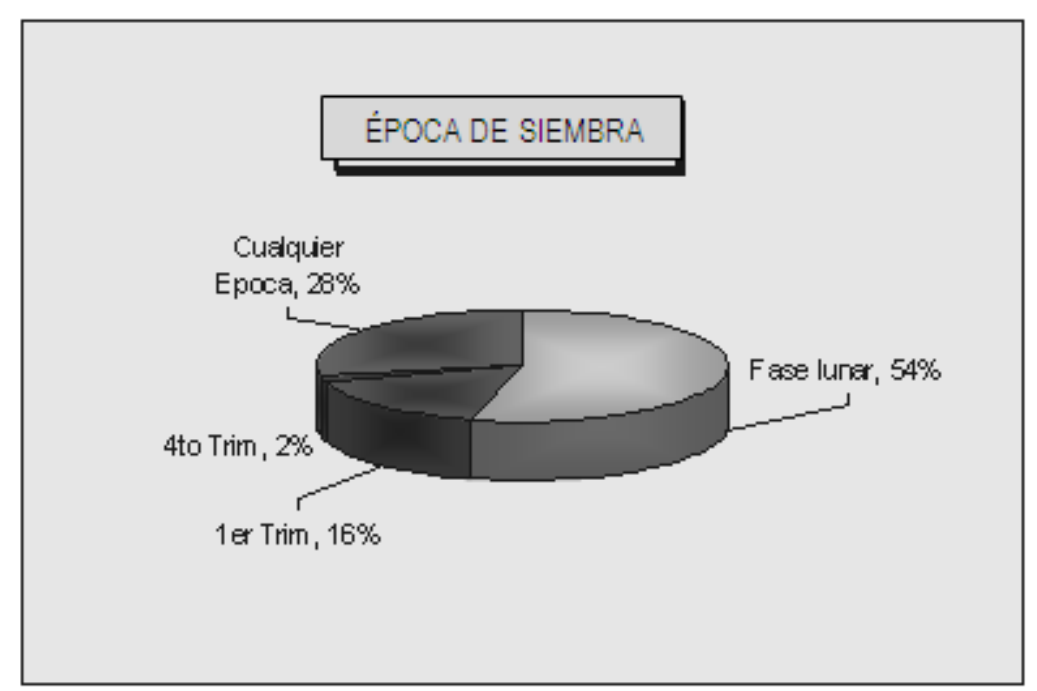

Figura 6. Época de siembra.

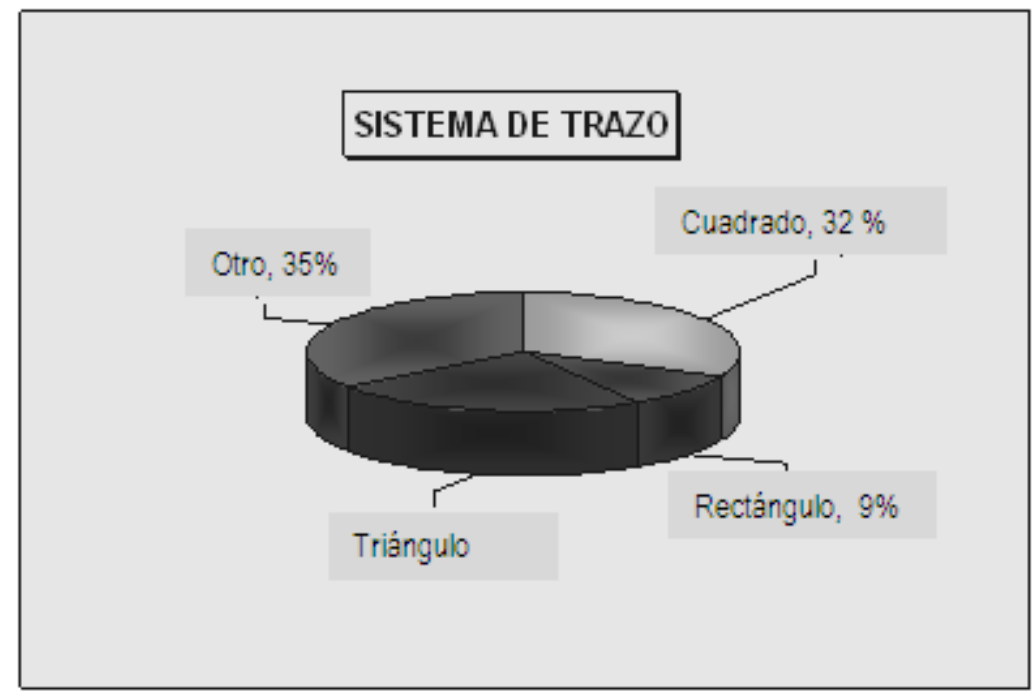

Figura 7. Orientación del cultivo.

Los productores de Dominico-Hartón aplican diferentes criterios para elegir la distancia de siembra de su cultivo. En la Figura 8 se presentan los porcentajes de cada criterio, el 35\% por experiencia siembra en cuadro a $2 \mathrm{~m} \times 2 \mathrm{~m}$. Las distancias técnicas recomendadas dependen de la fertilidad del suelo y el tipo de trazo para la obtención de una población determinada por hectárea (CORPOICA, 2002). 


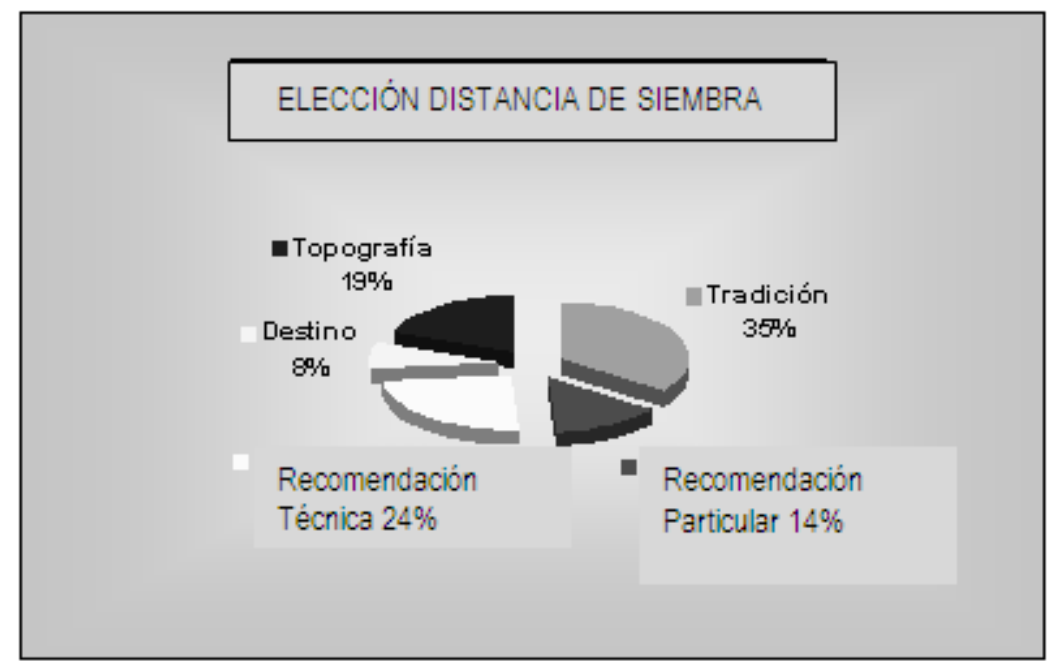

Figura 8. Elección distancia de siembra.

En las Figuras 9 y 10 se muestran los criterios de selección de semilla.

Según las recomendaciones técnicas del cultivo lo ideal es que el productor genere su propia semilla, sin embargo, desconocen las metodologías de producción rápida y sana en la propia finca.

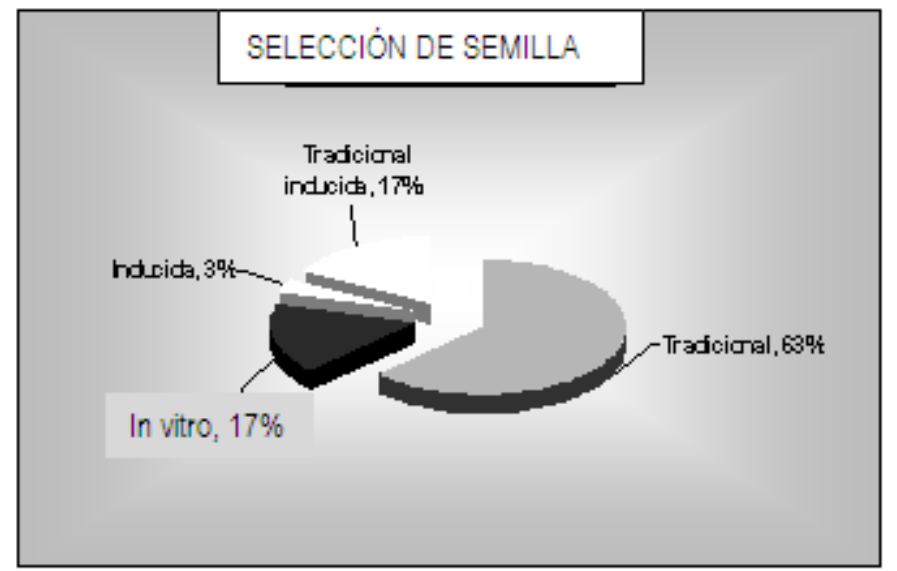

Figura 9. Criterios de selección de semilla. 


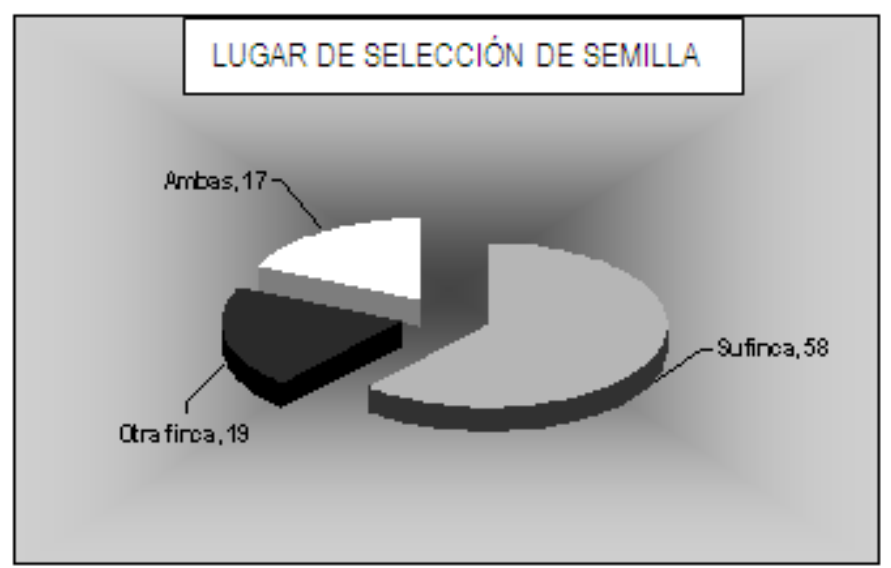

Figura 10. Procedencia de las semillas.

En cuanto a la forma de siembra se encontró que el $80 \%$ de los productores utilizan un solo colino por hoyo, mientras que el $20 \%$ emplean dos colinos por hoyo. De acuerdo con los productores encuestados, se emplean dos semillas cuando estas son de poco tamaño o de baja calidad. La tendencia mayoritaria es dejar por fuera parte del seudotallo de la semilla en el momento de la siembra. La mejor opción es enterrar la semilla completamente para evitar que se deshidrate y que depositen insectos o plagas de importancia económica (Aránzazu et al., 2002). La mayoría de los productores (83\%) hacen correctamente la labor de corte de seudotallo, la cual garantiza poca incidencia de plagas en el cultivo, mientras que el $17 \%$ no lo hace. Uno de los hallazgos críticos encontrados es que el $36 \%$ de los productores no realizan la práctica de desinfección de colinos. El 45\% utiliza insecticidas, el $7 \%$ bactericida, el $6 \%$ con fungicidas y el $6 \%$ restante utiliza otros productos químicos como veterina, formol, entre otros. La desinfección se hace especialmente para combatir el problema de nematodos, sin embargo, si la semilla va infectada con alguna enfermedad bacteriana o plaga que se encuentre dentro del cormo, esta labor resulta ineficaz, por lo tanto el uso de bactericidas y fungicidas no es recomendable (Robinson y Galán, 2011). No obstante, se encontró que el $47 \%$ de los productores clasifica el colino por calidad, el 39\% asume criterios de tamaño y sanidad y el $14 \%$ por su tipo.

Dentro de las prácticas de manejo del cultivo de plátano se tienen como criterios de fertilización los posibles correctivos de suelos, tipos de fertilizantes (compuestos y simples), así como el criterio para aplicarlos. El $40 \%$ de los encuestados lo hacen por experiencia personal, el $20 \%$ por observación a otros, igualmente un $20 \%$ por el análisis de suelo y el $19 \%$ por criterio técnico, solamente el $1 \%$ los aplica sin criterio definido. En general, el $73,4 \%$ de los productores realizan fertilización y el $26,6 \%$ de los productores no realizan esta práctica.

Durante los primeros estados de desarrollo las malezas le restan vigor a las plantas, por lo que debe hacerse un corte cada seis semanas dependiendo de su crecimiento y de la efectividad de los controles químicos (CORPOICA, 2002). Los productores de 
esta zona realizan un control de tipo manual, químico y mecánico, como se observa en la Figura 11. Los químicos más utilizados en orden de uso y totalmente prohibidos según legislación colombiana (Decreto 1843 de 1991; Ley 822 de 2003) son el Glifosato, Dithane y Round Up como se muestra en la Figura 12.

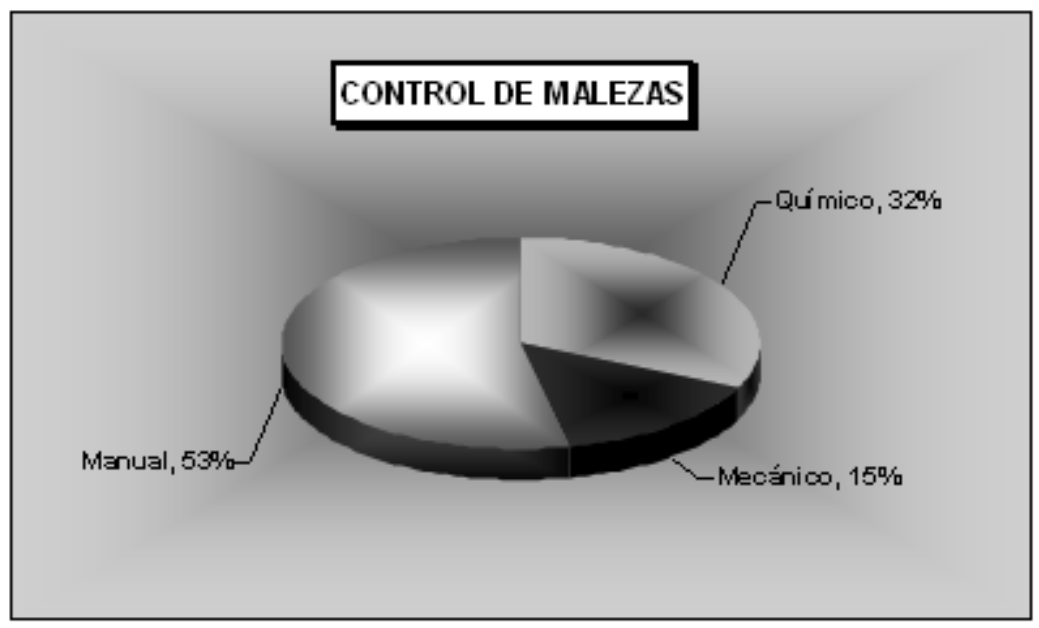

Figura 11. Control de malezas.

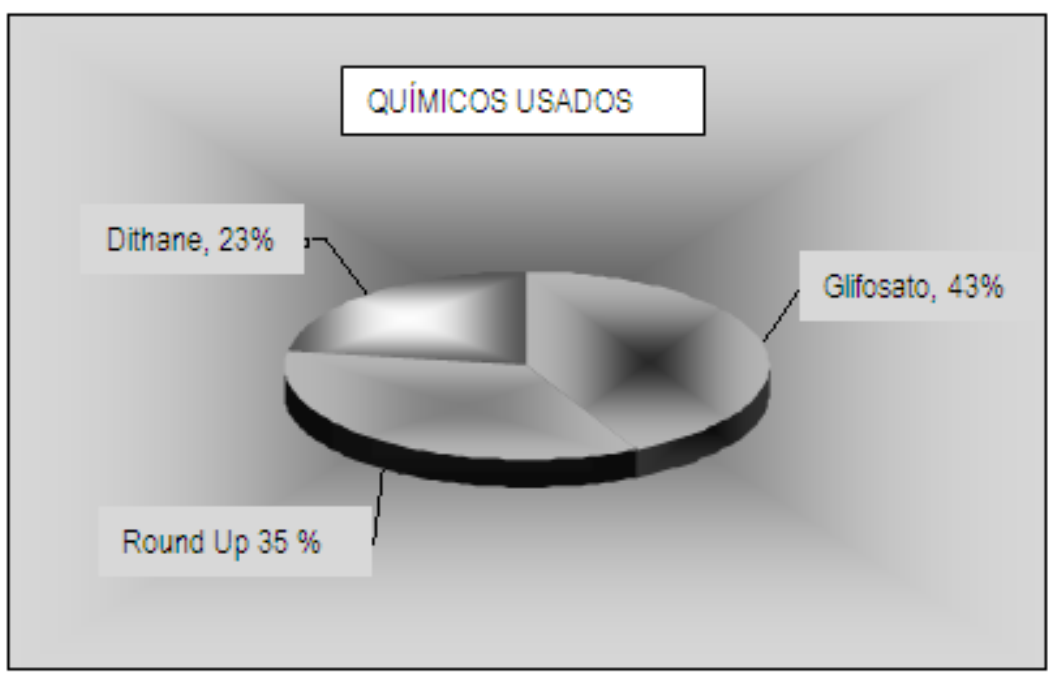

Figura 12. Químicos utilizados en el control de malezas.

Las enfermedades de las plataneras en general se manifiestan con encrespamientos o rasgaduras de las hojas, acompañados en ocasiones por amarillamiento y secamientos; o también por agentes patógenos como virus, bacterias, hongos y nematodos (Robinson y Galán, 2011). La prevalencia de enfermedades en esta zona correspondieron al 53\% Sigatoka amarilla (Mycosphaerella musicola), cuyos efectos en las plantaciones son pérdida parcial o total del follaje, reducción del vigor, pérdida de peso de los racimos y maduración precoz de los mismos, 
afectando la calidad y rendimientos de los cultivos. En menor proporción se encontró la presencia de otras enfermedades como se muestra en la Figura 13. Como respuesta a la presencia de un número significativo de patologías, se confirma que las prácticas para los tratamientos son deficientes, además de que el $41 \%$ no ejerce ningún control (Figura 14).

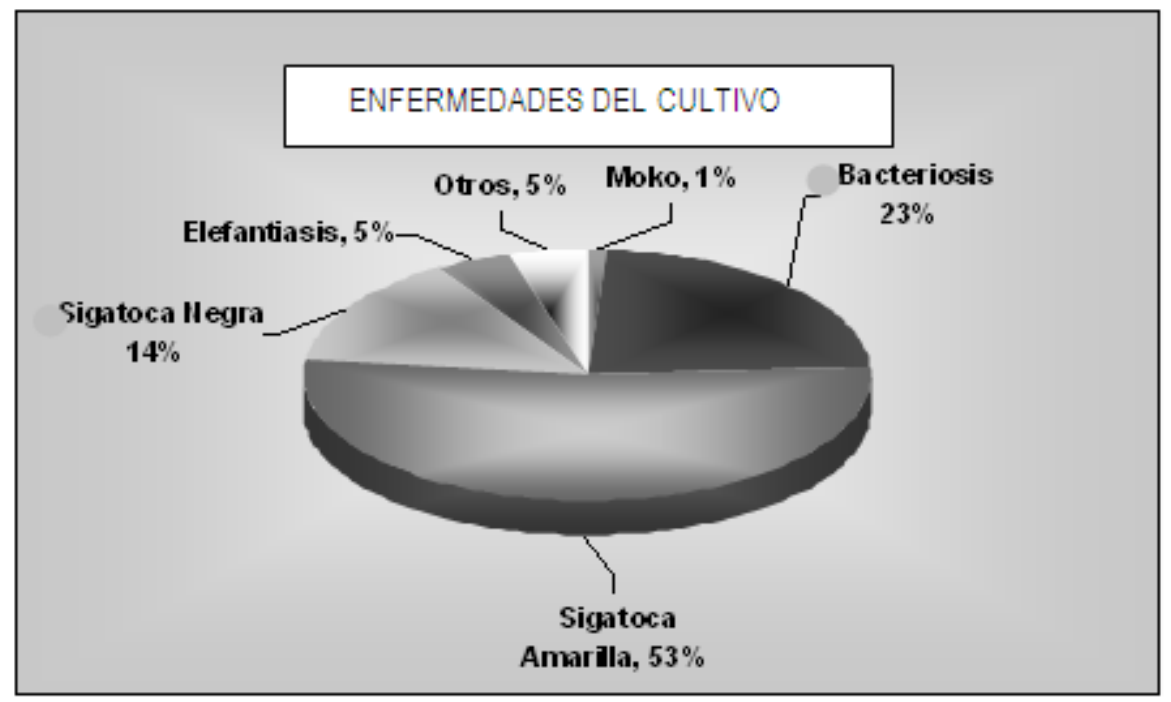

Figura 13. Enfermedades más comunes.

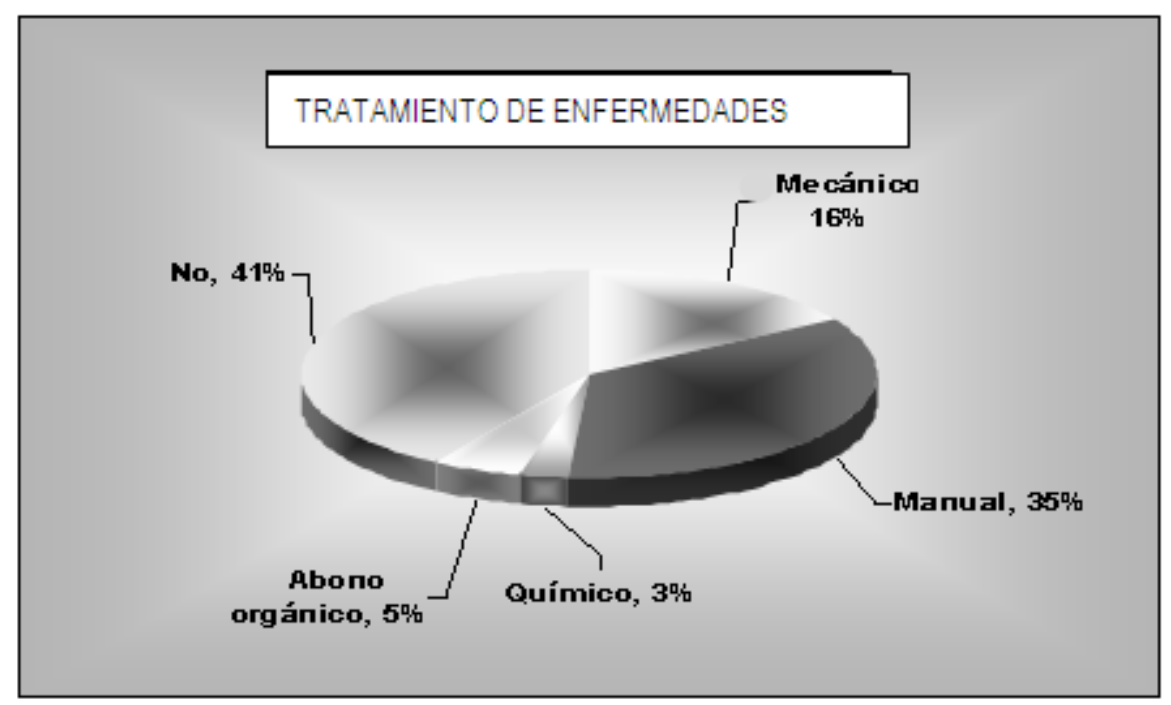

Figura 14. Tratamientos utilizados en el control de malezas.

Como medidas preventivas hacia la diseminación de enfermedades, una de las prácticas agrícolas más empleadas es la desinfección de herramientas, encontrándose para esta zona platanera un $63 \%$ renuente y negligente a esta actividad, solamente el $37 \%$ realizan bien esta práctica. Con relación a las plagas que atacan el cultivo del plátano en esta zona se encontró un $27 \%$ picudo rayado (Metamasius hemipterus), 20\% picudo 
negro (Cosmopolites sordidus Germen), 17\% hormigas, 13\% gusano peludo (Antichloris sp.), 11\% Caterpillar (Ecphantheria spp.), 6\% gusano tornillo (Castniomera humboldti), cucarrones $(4 \%)$, y otras plagas $(2 \%)$.

Para el control se utilizan químicos (22\%) como insecticidas, sin ningún criterio técnico o especializado, prefiriendo los de fácil consecución en el mercado como Furadan, Malathion, Lorsban y hasta fungicidas como el Dithane, actualmente prohibidos. El $18 \%$ emplea la trampa con Beauveria bassiana, el $7 \%$ embolsan, el $6 \%$ prácticas de control manual, el $4 \%$ utilizan trampas de seudotallo, el $2 \%$ control biológico. El $38 \%$ de la población muestreada no realiza ningún control de plagas.

Con respecto a las labores culturales están el deshoje, descalcete, descoline y destronque como prácticas ancestrales básicas para el manejo de las plantaciones de plátano. En este aspecto los productores realizan en un $100 \%$ las labores de deshoje y descoline, un $60 \%$ el descalcete, el destronque $73 \%$, gradual y el $27 \%$ lo realizan de manera inmediata. En general estas prácticas culturales son utilizadas para minimizar problemas de plagas y enfermedades que de no hacerlas periódicamente sacrificarían el proceso biológico normal y la estética de las plantaciones. Se pretende con estas prácticas prolongar la vida útil del cultivo, obtener mayores rendimientos, además de que se evita la contaminación ambiental.

En la cosecha se determinó que una vez cosechado el racimo, el seudotallo no incide sobre su peso en la misma cepa; el 25\% de la población al cosecharlo lo deja intacto. El 43\% lo corta a la mitad y más de la mitad y el $53 \%$ hace correctamente la labor de cortar y picar. En la etapa de poscosecha frente al empaque predomina la venta de volúmenes en racimo (81\%), canastilla (17\%), guacal y bulto (1\%) respectivamente, lo cual se refleja en mayores ganancias para el intermediario y baja rentabilidad para el productor según los encuestados.

Los residuos de la cosecha y poscosecha del plátano DominicoHartón son aprovechados como alimento para animales (6\%), consumo interno (13\%), industrialización, abonos orgánicos y en menor proporción son botados en lugares alejados generando hospedero de plagas y contaminación ambiental. Cuando se trata de producción de segundas y terceras se comercializan, para consumo animal o son utilizadas como abono orgánico.

\section{CONCLUSIONES Y RECOMENDACIONES}

La población productora de plátano del bajo Occidente del departamento de Caldas tiene como actividad agrícola principal en orden de importancia el plátano y el café. La mayoría oscilan entre 51 y 60 años de edad con un nivel de escolaridad bajo. La mano de obra es contratada. La mayoría de los cultivos están en terrenos menores a 10 hectáreas sin tecnificación, aún muy arraigados al uso de sustancias químicas para el control de las 
enfermedades propias del plátano como la Sigatoka negra y amarilla. En el manejo del cultivo la mayoría no tienen apropiadas las Buenas Prácticas Agrícolas (BPA) como desinfección de herramientas, desinfección de colinos y falta de conocimientos técnicos frente al uso de fertilizantes. Las labores culturales propias de la actividad agrícola del plátano son muy arraigadas y bien desarrolladas, por lo que ha impactado positivamente en la reducción de la contaminación ambiental, además del incremento de los recursos e ingresos lo cual ha generado una elevada actitud del productor hacia la capacitación en tecnologías apropiadas. Al dar valor agregado a los residuos de cosecha y poscosecha, existe la posibilidad de generar empleos directos e indirectos, con lo cual se contribuye al desarrollo de la región y al beneficio de la población. Los productores involucrados en la actividad de plátano no son de subsistencia total, sino más bien son productores con un alto sentido de diversificación, con otras fuentes de ingresos alternativos y diversas experiencias laborales agrícolas, con el principal objetivo de mejorar su calidad de vida. En conclusión, la asistencia técnica y los programas de transferencia de tecnología reflejan en este estudio deficiencias notorias que no han sido de impacto positivo para el productor, por lo tanto no se pueden concebir planes de desarrollo sin conocer la realidad regional, que por medio de herramientas como este tipo de diagnósticos socioeconómicos y tecnológicos arrojan una visión de la problemática que afronta la comunidad para poder formular soluciones a corto plazo a los problemas antes mencionados. Se deben implementar mejores estrategias de capacitación y tecnologías de producción más limpia, para incrementar la producción y mejorar la calidad del producto, con miras al mejoramiento de la comercialización y el acceso a mejores precios, aumentando así la rentabilidad para el productor.

\section{REFERENCIAS}

- AGRONET. (2012). Reportes estadísticos, producción nacional por producto. Colombia: Ministerio de Agricultura y Desarrollo Rural.

- Aranzazu, F., Valencia, J., Arcila, M.I., Castrillón, C., Bolaños, M.M., Castellanos, P.A., Pérez, J.C. y Rodríguez, J.L. (2002). El Cultivo de plátano. En Manual Técnico (pp. 80-82). Manizales: CORPOICA.

- Corporación Colombiana de Investigación Agropecuaria (CORPOICA). (2002). Manejo Integrado del Cultivo del Plátano: Manual Técnico. Bogotá: Autor.

- Corporación Colombia Internacional (CCI). (2000). Inteligencia de Mercados, Plátano, Perfil del Producto. Ministerio de Agricultura y Desarrollo Rural. pp. 1-11.

- DANE. (2013). Encuesta Nacional Agropecuaria ENA-2012. Recuperado http://www.dane.gov.co/files/investigaciones/agropecuario/en al

boletin_ena_2012.pdf 
- Espinal G., C.F. (2005). La Cadena del Plátano en Colombia. Una Mirada Global de su Dinámica y Estructura. Documento de Trabajo 61. Ministerio de Agricultura, Observatorio Agrocadenas Colombia. p. 2.

- Decreto 1843. (1991). Uso y manejo de plaguicidas. Santa Fe de Bogotá, D.C.: Presidencia de la República.

- Gobernación del Departamento de Caldas. (2008). Registro de Usuarios de Asistencia Técnica-RUAT). Manizales.

- INFOAGRO. (2005). El cultivo del plátano (1a. parte). Recuperado de http://www.infoagro.com/frutas/frutas_ tropicales/platano.htm

- Ley 607. (2000). Modificación de la creación, funcionamiento y operación de las Unidades Municipales de Asistencia Técnica Agropecuaria, UMATA, y reglamentación de la asistencia técnica directa rural en consonancia con el Sistema Nacional de Ciencia y Tecnología. Santa Fe de Bogotá, D.C.: Ministerio de Agricultura y Desarrollo Rural de la República de Colombia.

- Ley 822. (2003). Normas relacionadas con los agroquímicos genéricos. Bogotá: Instituto Colombiano Agropecuario (ICA) I Ministerio de Agricultura y Desarrollo Rural / Ministerio de Ambiente, Vivienda y Desarrollo Territorial.

- Mejía G., L.F. (2013). Evaluación del comportamiento físico y químico poscosecha del plátano Dominico-Hartón (Musa $A A B$ simmonds) cultivado en el municipio de Belalcázar (Caldas). Trabajo de grado. Facultad de Ciencias. Universidad Nacional de Colombia. Santafé de Bogotá.

- Moreno M., J.M., Blanco U., C. y Mendoza T., R.J. (2009). Buenas Prácticas Agrícolas en el cultivo del banano en la región del Magdalena. Primera edición. Medellín: Editorial Comunicaciones Augura.

- Ramírez, C., Castaño, J., Villegas, B. y Aristizábal, M. (2013). Efecto de inductores de resistencia sobre las Sigatokas negra (Mycosphaerella fijiensis Morelet) y amarilla (Mycosphaerella musicola Leach) en plátano. Revista U.D.C.A. Actualidad \& Divulgación Científica, 15(2): 363-371.

- Robinson, J.C. y Galán S., V. (2011). Plátanos y bananas. España: Ediciones Mundi-Prensa.

1. Docentes Departamento de Ingeniería, Universidad de Caldas, Calle 65 No. 26-10, Manizales, Caldas, Colombia. www.ucaldas.edu.co, lileon@ucaldas.edu.co, luis.mejia_@ucaldas.edu.co,Immontesra@gmail.com.co

Para citar este artículo: León-Agatón, L., Mejía-Gutiérrez, L.F. y Montes-Ramírez, L.M. (2014). Caracterización socioeconómica y tecnológica de la producción del plátano en el bajo Occidente del departamento de Caldas. Revista Luna Azul 41, 184-200. Recuperado de http://lunazul.ucaldas.edu.co/index.php?option=content\&tas k=view\&id=1062 